\title{
INCREASE THE SMART CITIES DEVELOPMENT BY USING AN INNOVATIVE DESIGN FOR VERTICAL AXIS WIND TURBINE
}

\author{
Ion Mălăel, Bogdan George Gherman \& Ionuţ Porumbel
}
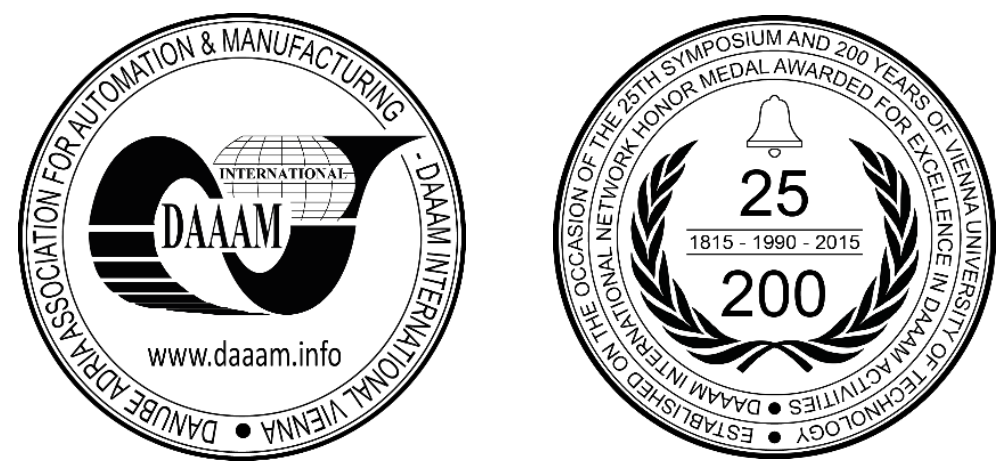

This Publication has to be referred as: Malael, I[on]; Gherman, G[eorge] B[ogdan] \& Porumbel, I[onut] (2016). Increase the Smart Cities Development by Using an Innovative Design for Vertical Axis Wind Turbine, Proceedings of the 27th DAAAM International Symposium, pp.0506-0513, B. Katalinic (Ed.), Published by DAAAM International, ISBN 978-3-902734-08-2, ISSN 1726-9679, Vienna, Austria

DOI: $10.2507 / 27$ th.daaam.proceedings.076

\begin{abstract}
In the actual urban development context, the smart city concept is frequently used. This concept has not an unique definition, but is always defined as of positive impact. At the base of this concept, is placed the challenge to reduce the environmental impact and the carbon footprint. Smart city is a system with people, financing, services, materials and also energy development. To create a sustainable smart environment is crucial to integrate different renewable energy, transport and data flows in city planning and management. However, the implementation of new technologies must be fitted with the existing structures. In this paper, we study a counter rotating vertical axis wind turbine. To investigate the flow in this new concept we used the CFD methods. For solving the Navier-Stokes system equation the commercial CFD ANSYS Fluent was used. The vorticity magnitude and the momentum and power coefficient variation by blade position resulting from the numerical simulations are presented.
\end{abstract}

Keywords: Smart city; wind energy; VAWT; CFD; power coefficient.

\section{Introduction}

The biggest challenge of our times is the development of cities into intelligent and sustainable environments. In the EU's energy policy the smarter energy systems play a key role. The targets of EU for 2020 are to consume $20 \%$ less energy, to increase the share of renewable energy to $20 \%$ and to reduce greenhouse gas emissions by $20 \%$ [1]. The problems associated with the energy sector and climate changes are the top priorities for the EU agenda. The ever diminishing oil resources, combined with ecological concerns have led to a focused attention on renewable energy, which should be inexhaustible and pollutant free [2]. Without the use of fossil fuels, without the change of natural course of rivers and without emitting any green house gases, wind energy has proven itself as a viable solution to the energetic independency of EU member countries. Therefore, the development of wind farms continues to be a successful endeavor, particularly in the EU [3] where multiple member states have already joined the forefront of wind turbine engineering.

The main objective of the smart energy system is to mitigate the environmental impact (climate change) due to the population increase [4]. It became more and more important to optimize all the processes of energy generation and consumption. 
The smart energy system allows to integrate energy from unpredictable and intermittent renewable sources and to distribute power much more efficiently [5]. A smart system will deliver electricity more cost-effectively and with lower greenhouse gas emissions (Fig. 1).

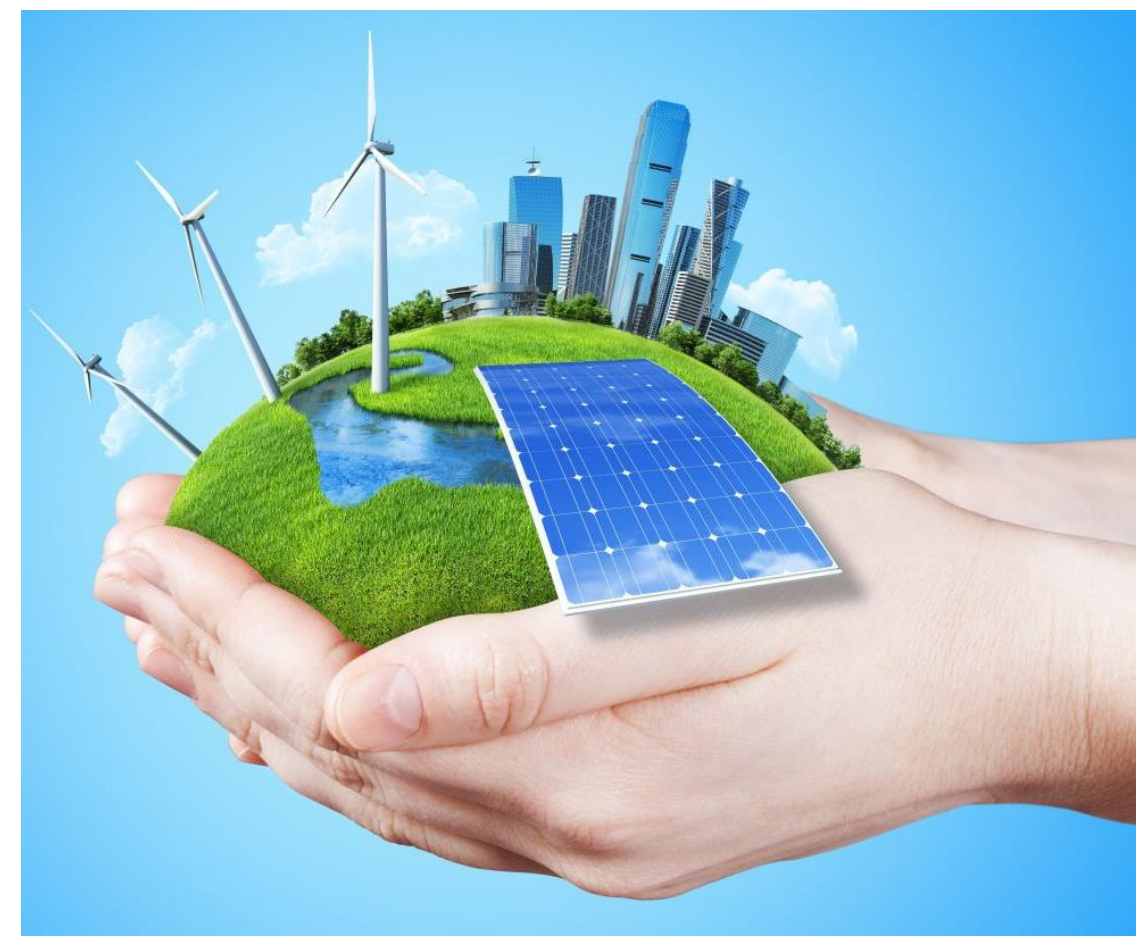

Fig. 1 Schematic smart energy system [6]

It was estimated that in the Earth's wind the available energy is around 10 million MW [7]. Wind turbines are of two types, Horizontal Axis Wind Turbine (HAWT) and Vertical Axis Wind Turbine (VAWT). VAWT is mostly viable for places with low wind speed regimes where HAWT is highly uneconomical [8]. The combination of two vertical axis wind turbines was studied by many researchers [9-11]. The common combination is between Darrieus and Savonius [12-14]. This configuration, Darrieus-Savonius was done to help Darrieus wind turbine at the starting moment. It's well known [15] that Savonius rotor creates high torque and is self-starting even at low wind speeds, but is relatively low in efficiency rating. The Darrieus rotor is not a self starting rotor [16], but has much higher efficiency than the Savonius rotor. The combination of rotors increases the total power of the turbine in lower wind speeds [17]. The advantages of VAWT are based on the wind direction independency, but also on the simple design and low cost.

A new counter rotating (CR) VAWT concept was developed at COMOTI. The concept is a combination between two VAWT Darrieus H-type wind turbines, placed concentricallyas shown in Fig. 3, and rotating in opposite directions. A Permanent Magnet Generator (PMG - Fig. 4) is placed on the common rotation axis of the two turbines, and consists in a set of permanent mangnets rotating together with inner wind turbine, and a set of inductance coils, rotating together with the outer wind turbine. The relative movement achieved between the magnets and the coils produces the electrical power generated by the assembly. One of main the advantages of the new concept are related to the fact that it contains no statinary parts, as the two armatures of the PMG (one with permanent magnets and one with coils) will rotate, but in opposite directions. Also, the fact that the two armatures are both rotating increases the relative speed between them, and, consequently, the magnetic field variation rate through the coils increases, leading to the production of more electrical power.

A small model of CR-VAWT with three straight blades will be designed, manufactured and studied in the NRDI COMOTI's wind tunnel. The blades airfoil used is NACA 0021 [18]. In this study, a series of numerical analyses on was carried out in order to validate a new concept. Usually, wind turbine can generate electric power only when it reaches certain speed [19], so the tests will be carried out at 3 wind speeds. The maximum current velocity of COMOTI's wind tunnel is $20 \mathrm{~m} / \mathrm{s}$. Also, to capture the streamlines and the interaction between this two VAWT the PIV installation will be used [20].

\section{Theoretical approach}

The vertical axis wind turbine Darrieus type is based on the lift force [21]. The Darrieus design consists of two or more blades attached to a vertical shaft. In Fig. 2, the forces and the three velocity vectors acting on the Darrieus VAWT are presented [22]. The orientation and magnitude of the drag $\left(\mathrm{F}_{\mathrm{D}}\right)$ and lift $\left(\mathrm{F}_{\mathrm{L}}\right)$ forces and the resultant force $\left(F_{R}\right)$ are also represented. The $F_{R}$ can also be decomposed into a normal force $\left(F_{N}\right)$ and a tangential force $\left(F_{T}\right)$. 


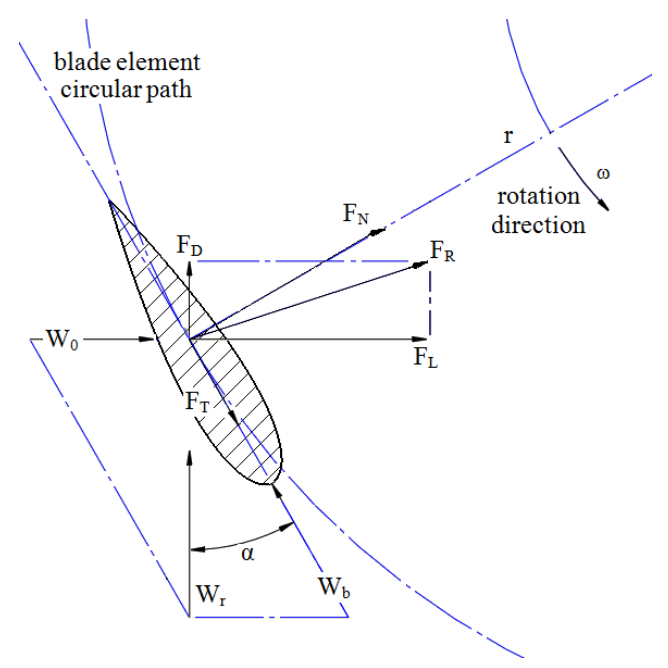

Fig 2. Force components and velocity and for VAWT Darrieus type

For a VAWT rotor with $\mathrm{N}$ blades, the average lift and drag forces can be defined as [23]

$$
\begin{aligned}
& F_{L}=\frac{N c}{2 \pi} \int_{z=0}^{H} \int_{\theta=0}^{2 \pi} q\left(-C_{N} \sin \theta_{b}+C_{T} \cos \theta_{b}\right) d \theta_{b} d z \\
& F_{D}=\frac{N c}{2 \pi} \int_{z=0}^{H} \int_{\theta=0}^{2 \pi} q\left(C_{N} \cos \theta_{b}+C_{T} \sin \theta_{b}\right) d \theta_{b} d z
\end{aligned}
$$

where:

$$
\begin{aligned}
& C_{N}=C_{L} \cos \varphi+C_{D} \sin \varphi \\
& C_{T}=C_{L} \sin \varphi-C_{D} \cos \varphi
\end{aligned}
$$

and $C_{L}$ and $C_{D}$ are the lift and drag coefficients.

The torque varies is function to azimuthal angle and the rotor height [24]. For a rotor with $\mathrm{N}$ blades, we have:

$$
T_{R}=\frac{c \omega}{2 \pi} \int_{z=0}^{H} \int_{0}^{2 \pi} q C_{T} r d \theta_{b} d z
$$

The average power is defined as [25]:

$$
P=\frac{N c \omega}{2 \pi} \int_{z=0}^{H} \int_{0}^{2 \pi} q C_{T} r d \theta_{b} d z
$$

So, the power coefficient can be obtained as [26]:

$$
C_{P}=\frac{P}{P_{\max }}=\frac{81}{64} \frac{1}{2 \pi} \frac{N c \omega}{\rho V_{\infty}^{3} R H} \int_{z=0}^{H} \int_{0}^{2 \pi} q C_{T} r d \theta_{b} d z
$$

\section{Geometry definition}

In this section, we present details about the geometry definition of the new vertical axis, Darrieus type wind turbinedeveloped at COMOTI. Fig. 3 presents the 3D virtual model of the wind turbine, developed using the SolidWorks software.

This turbine is designed to generate up to $2.5 \mathrm{~kW}$ power at a wind speed of $12 \mathrm{~m} / \mathrm{s}$. Two variants of the wind turbine, of different diameter and blade chords were studies. Table 1 shows the geometric parameters of the entire system in the two cases. Using the theoretical approach [27], the dimensions of the wind turbine rotors were defined. In this way, the characteristic dimensions, such as height and rotor diameter, were determined. Given that it is desired to have high turbine efficiency at values of TSR's (Tip speed ratio) as small as possible, a value of 0.5 was used for the first turbine 
solidity and 0.35 for the second one. Thus, using $\sigma=\frac{N c}{D}$ we determined the aerodynamic chord length of the vertical axis wind turbine blade.

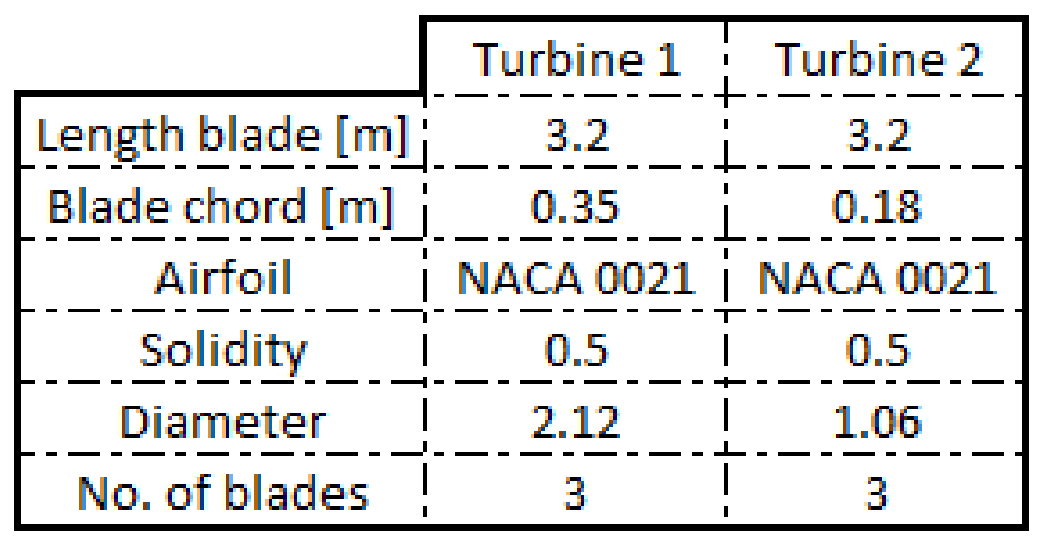

Table 1. Geometric parameters

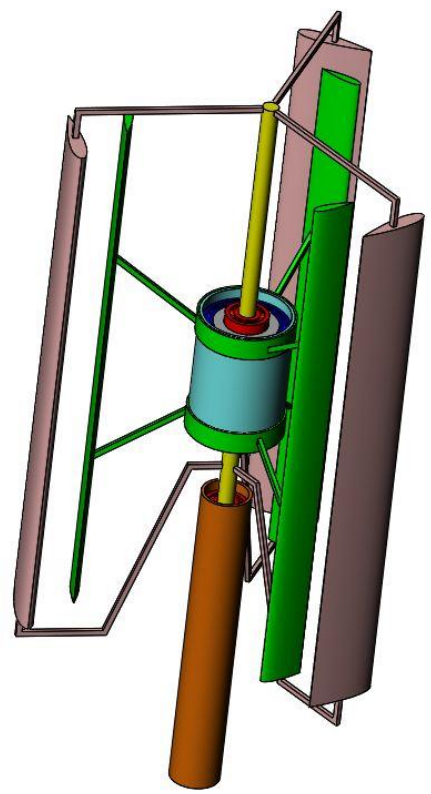

Fig. 3 CR-VAWT design

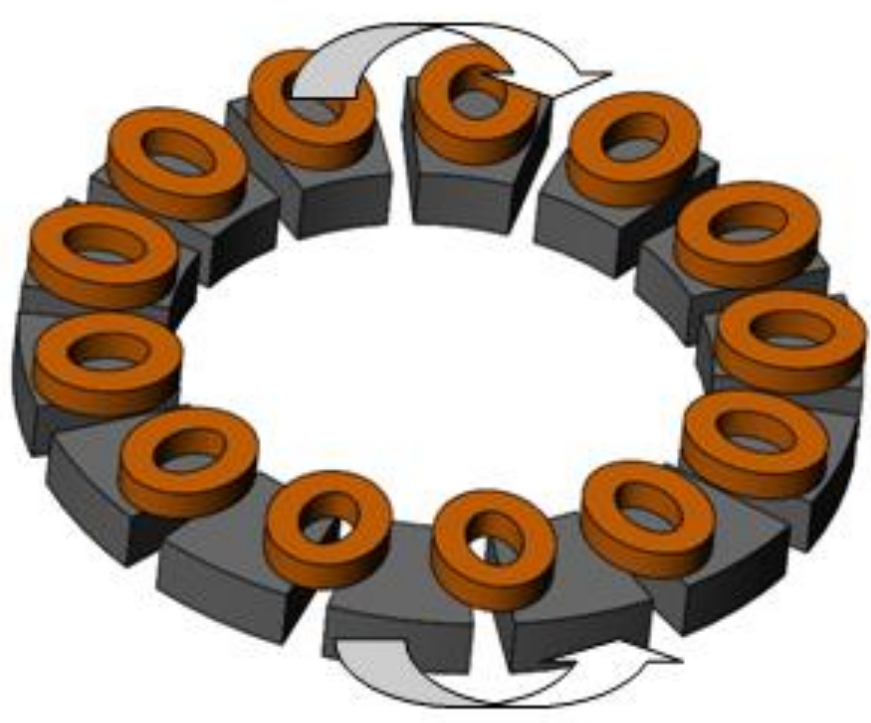

Fig. 4 Generator components and rotation directions

\section{CFD methods}

Starting from the operating parameters in table 1, we used the CFD (Computational Fluid Dynamics) approach to estimate the efficiency of this new CR(Counter-Rotating) -VAWT Darrieus type. In this case, we used the commercial code ANSYS-Fluent [28]. The SIMPLEC type pressure based solver with a second order upwind discretization scheme was used.

This presented numerical simulations use the URANS (Unsteady Reynolds Average Navier-Stokes) approach, with the k- $\omega$ SST turbulence model [29]. This model solves for two additional transport equations for the turbulent kinetic energy $(\mathrm{k})$ and the specific dissipation rate $(\omega)$ and combines two standard turbulence models, $\mathrm{k}-\varepsilon$ and $\mathrm{k}-\omega$. The first full turbulence model imagined was the $\mathrm{k}-\omega$ model. This model was introduced in 1941 by Kolmogorov [30].

The transport equation for the turbulent kinetic energy, $\mathrm{k}$ is written as [31]:

$$
\frac{\partial k}{\partial t}+\bar{u} \frac{\partial k}{\partial x}+\bar{v} \frac{\partial k}{\partial y}+\bar{w} \frac{\partial k}{\partial z}=\Gamma_{k}\left(\frac{\partial^{2} k}{\partial x^{2}}+\frac{\partial^{2} k}{\partial y^{2}}+\frac{\partial^{2} k}{\partial z^{2}}\right)+\tilde{G}_{k}-Y_{k}
$$


Also, the transport equation for the specific turbulent kinetic energy dissipation rate, $\omega$ has the form [32]:

$$
\frac{\partial \omega}{\partial t}+\bar{u} \frac{\partial \omega}{\partial x}+\bar{v} \frac{\partial \omega}{\partial y}+\bar{w} \frac{\partial \omega}{\partial z}=\Gamma_{\omega}\left(\frac{\partial^{2} \omega}{\partial x^{2}}+\frac{\partial^{2} \omega}{\partial y^{2}}+\frac{\partial^{2} \omega}{\partial z^{2}}\right)+G_{\omega}-Y_{\omega}+D_{\omega}
$$

where: $\Gamma_{k}$ and $\Gamma_{\omega}$ are the effective diffusivities for $\mathrm{k}$ and $\omega ; D_{\omega}^{+}$is the positive portion of the cross-diffusion term; $\widetilde{G}_{k}$ represents the production of turbulence kinetic energy; and $G_{\omega}$ represents the production of $\omega$.

This numerical study was conducted on a combination of two vertical axis wind turbines in a 2D domain. The computing domain consists of three fields with an interface at the boundary between them (Fig. 5). The rotor1 domain has a radius $\mathrm{R}=1.6 \mathrm{~m}$, and the stator domain is 6 times bigger. Also, in the Fig. 2 the mesh and the value of $\mathrm{y}+$ for all the blades are presented.
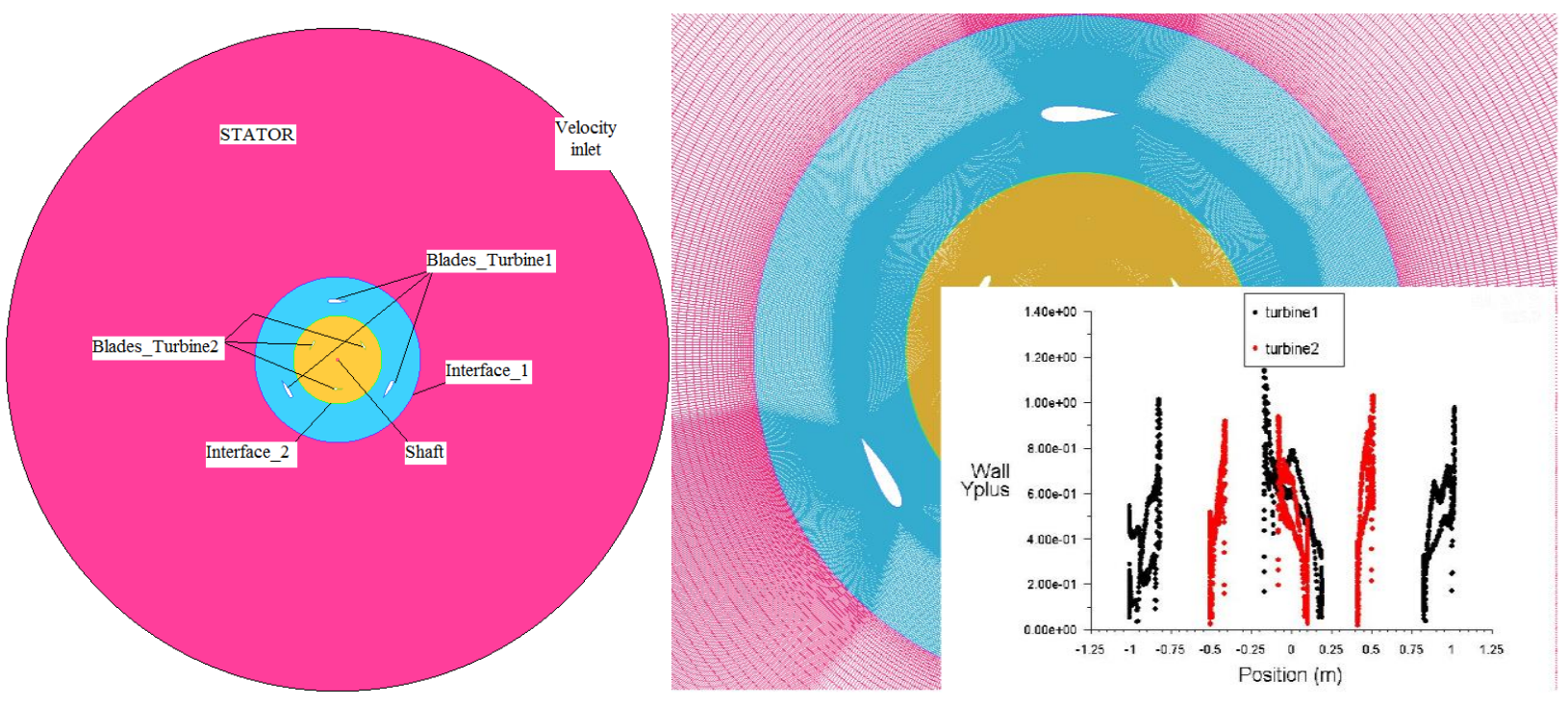

Fig. 5. Computational domain with y+ value for all blades

For the grid generation, the blocking method included in the ICEM CFD meshes software was used. To solve the problems that could occur in the boundary layer, the value of $\mathrm{y}+$ was maintained at values less than 1 , and the ratio of adjacent elements sizes was kept below 1.05 .

The boundary conditions were imposed so that the flow to be close to the real one. On the inlet of the stator domain a $12 \mathrm{~m} / \mathrm{s}$ velocity was imposed, normal to the boundary surface, and solid, no-slip wall boundary conditions were imposed on the blades and the shaft. Six cases were studied, with TSR values were set between 0.5 and 3 .

\section{Results}

Figs. 6 and 7 present, respectively, the vorticity magnitude for each TSR value and the power coefficient variation around the each of the two wind turbine: the outer turbine is denoted Turine 1, and the inner turbine is Turbine 2.

As the TSR increases, the vortical pattern resulting from the CFD simulation can be observed to change significantly. Thus, at low TSR, large vortices are detaching from each blade. The vortex trail oscillates downstream of each profiles due to the interaction between the inner and the outer blade networks. As the TSR increases, the interaction intensity increases, and the vortex trail tends to become attached to the trailing edges of both the inner and the outer blades. The vorticity intensity decreases, and the volume of the wake increases. At the highest TSR, the waves extend to cover almost the entire circumference of the circles on whch the blades are rotating, and they are deflected either inside, or outside, in an oscillatory motion, by the presence of the leading edge of the adjacent blade. 


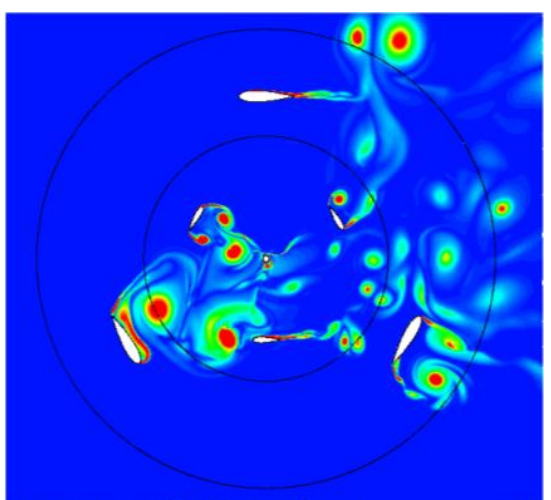

a)

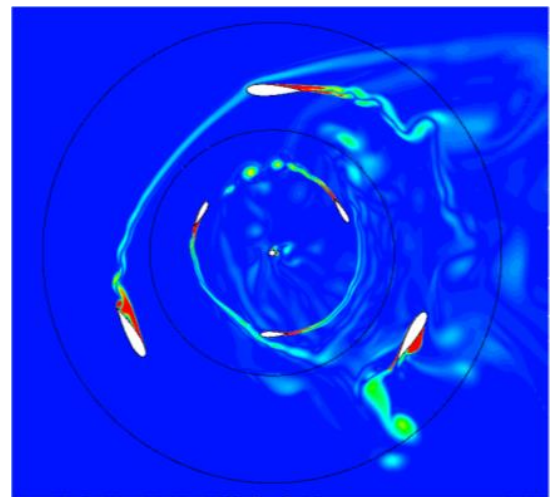

c)

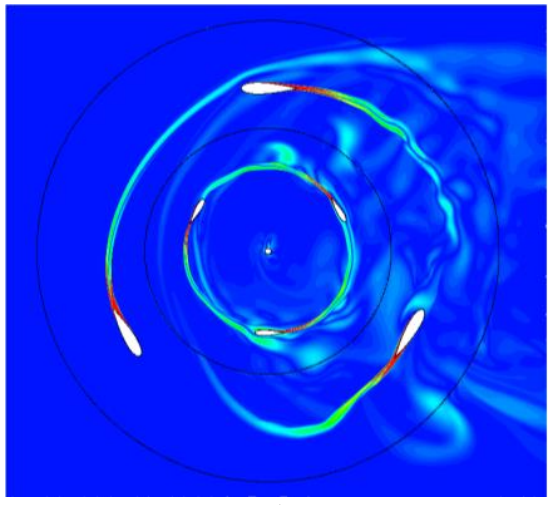

e)

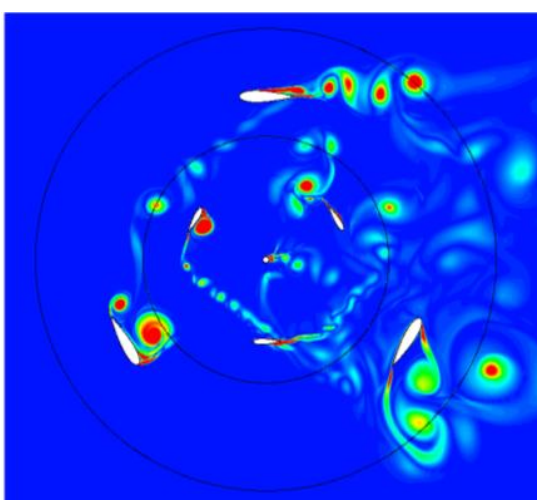

b)
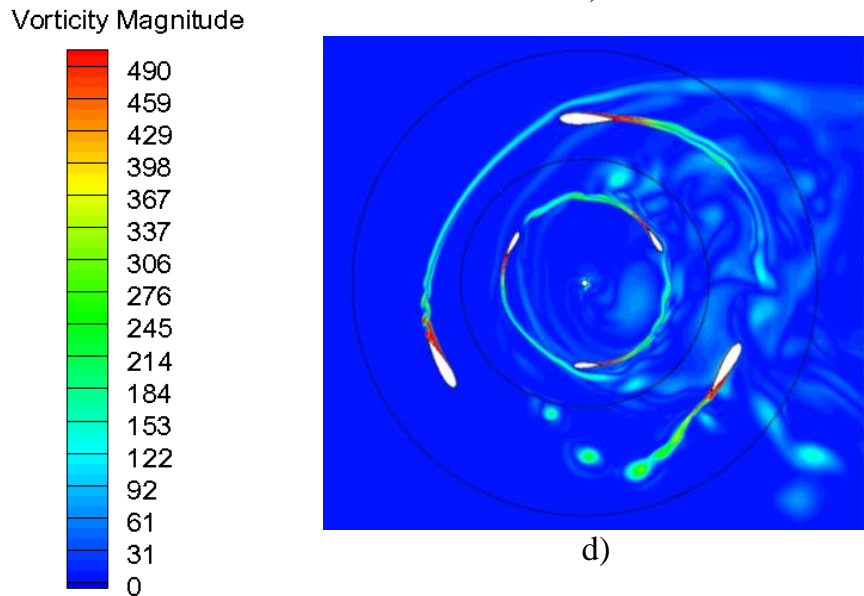

d)

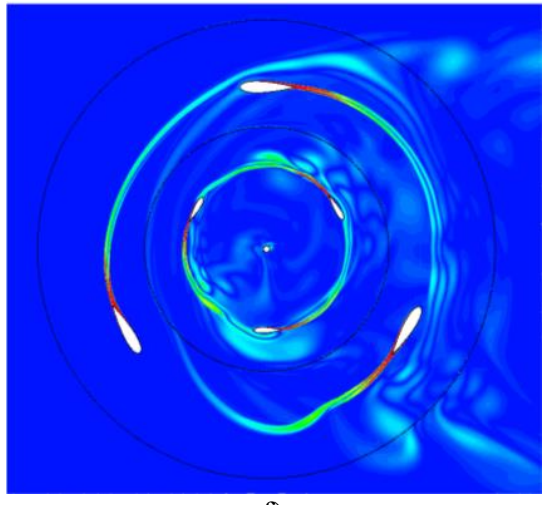

f)

Fig. 6. Vorticity magnitude for: a) TSR=0.5; b) TSR=1; c) TSR=1.5; d) TSR=2;

e) $\mathrm{TSR}=2.5 ;$ f) $\mathrm{TSR}=3$;

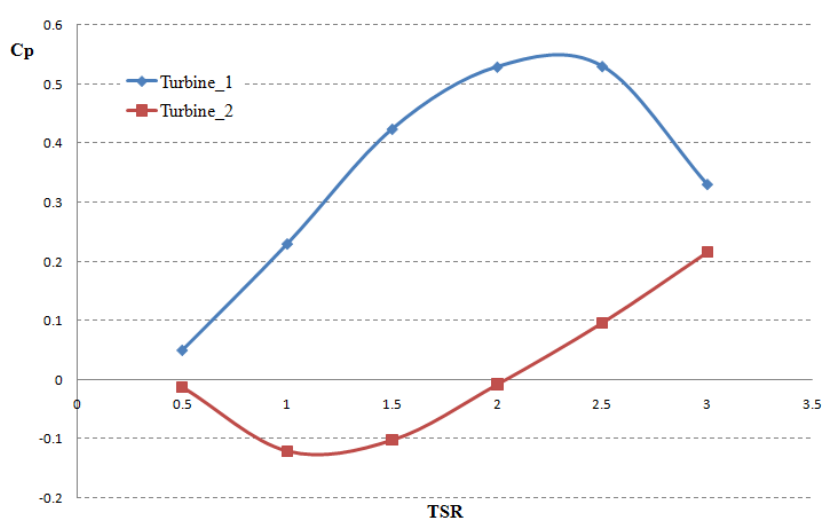

Fig. 7. Cp variations for each wind turbine 
Fig. 7 indicates an optimal TSR can be found with respect to the TSR value. Thus, the outer turbine power coefficient is maximum at about TSR $=2.4$.

\section{Conclusion}

In this paper work the flow field around new concept of Darrieus-type (lift-based) vertical axis wind turbine has been predicted numerically using CFD method, namely URANS. Both the wind turbines flow has been analised. The study has been conducted to determine the influence of the inner turbine on the global turbine efficiency. It is found that this influence has a positive impact on the overall turbine performance, due to the interaction of the wakes generated by the two blade networks rotating in opposite directions. An optimium value is found at TSR $=2.4$.

The simulations presented here use standard NACA 0021 airfoils, but optimization methods, such as Genetic Algorithms (GA) [33], or ANN [34] can be used to increase also the efficiency of the assembly.

This paper contributes to a better understanding of the flow field around vertical axis wind turbines and suggests strongly that accurate modeling of the unsteadiness effects is an essential condition to high fidelity prediction of the aerodynamics performance of such devices.

\section{References}

[1] "Cities, towns \& Renewable energy" @ O OECD/IEA, 2009 International Energy Agency

[2] Renewable energy world, jan 1999

[3] European Wind Energy Association, EU energy policy after 2020, www.ewea.org,2011

[4] José Miguel Guzmán, George Martine, Gordon McGranahan, Daniel Schensul, Cecilia Tacoli, "Population Dynamics and Climate Change", Copyright (C) UNFPA and IIED, 2009 ISBN: 978-0-89714-919-8

[5] Bethany Speer, Mackay Miller, Walter Shaffer, Leyla Gueran, Albrecht Reuter, Bonnie Jang, Karin Widegren, „The Role of Smart Grid in Integrating Renewable Energy”, Technical Report NREL/TP -6A20- 63919 May 2015

[6] http://www.citi.io/2015/12/29/the-top-3-smart-city-trends-to-expect-in-2016/

[7] Søren Krohn, Poul-Erik Morthorst, Shimon Awerbuch, "The Economics of Wind Energy" - By the European Wind Energy Association, March 2009

[8] Malael, I[on]; Dragan, V[aleriu] \& Gherman, G[eorge] B[ogdan] (2016). Turbulence Intensity Effects on the Vertical Axis Wind Turbine Starting Efficiency, Proceedings of the 26th DAAAM International Symposium, pp.0974-0979, B. Katalinic (Ed.), Published by DAAAM International, ISBN 978-3-902734- 07-5, ISSN 17269679, Vienna, Austria DOI: 10.2507/26th.daaam.proceedings.137

[9] Lucia-Andreea Mitulet*, Gabriela Oprina, Rares-Andrei Chihaia, Sergiu Nicolaie, Adrian Nedelcu, Mihail Popescu (2014). Wind Tunnel Testing for a New Experimental Model of Counter-Rotating Wind Turbine, 25th DAAAM International Symposium on Intelligent Manufacturing and Automation, DAAAM 2014

[10] P. Kacor, S. Misak, L.Prokop, Modification of construction design of vertical axis wind turbine, Annals of DAAAM for 2011 \& Proceedings of the 22nd International DAAAM Symposium, Volume 22, No. 1, ISSN 17269679, ISBN 978-3-901509-83-4, Published by DAAAM International, Vienna, Austria, EU, 2011

[11] Anurag Kumar, et al." Hybrid Kinetic Turbine Rotors: A Review", [IJESAT] [International Journal of Engineering Science \& Advanced Technology, Volume-4, Issue 6, 453-463, ISSN: 2250 - 3676

[12] Ali M.E. Estimation of the Performance of the Darrieus - Savonius combined machine. In: Ecologic Vehicles and Renewable Energies, Monaco, Germany, March 26 - 292009

[13] Gupta R., Das, R. and Sharma, K.K. Experimental study of a Savonius-Darrieus wind machine. In: International Conference on Renewable Energy for Developing Countries, University of Columbia, Washington DC, 2006

[14] K.K. Sharma, A.Biswas, R. Gupta, "Performance Measurement of a Three-Bladed Combined Darrieus-Savonius Rotor”, INTERNATIONAL JOURNAL of RENEWABLE ENERGY RESEARCH A.Biswas et al., Vol.3, No.4, 2013

[15] Abdullah Al-Faruk,Ahmad Sharifian, "Geometrical optimization of a swirling Savonius wind turbine using an open jet wind tunnel", Alexandria Engineering Journal, Available online 30 July 2016, http://dx.doi.org/10.1016/j.aej.2016.07.005

[16] A.R. Senguptaa, A. Biswasa,R. Guptab, "Studies of some high solidity symmetrical and unsymmetrical blade HDarrieus rotors with respect to starting characteristics, dynamic performances and flow physics in low wind streams", Renewable Energy Volume 93, August 2016, Pages 536-547, http://dx.doi.org/10.1016/j.renene.2016.03.029

[17] Saha U.K., Rajkumar M. J. (2005), on the performance analysis of Savonius rotor with twisted blades, Renewable Energy, 31, pp. 1776-1788 
[18] MĂLĂEL, Ion; DRĂGAN, Valeriu; VIZITIU, Georgel, „The vertical axis wind turbine efficiency evaluation by using the CFD methods", Applied Mechanics \& Materials . 2015, Vol. 772, p90-95. 6p

[19] Kirke, Brian Kinloch, 1998. "Evaluation of Self-Starting Vertical Axis Wind Turbines for Stand-Alone Applications". Griffith University, Australia. Retrieved from http://www4.gu.edu.au:8080/adt-root/public/adtQGU20050916.120408/ on November 1, 2005

[20] Hofemann, C., Sim ao Ferreira, C., Dixon, K., van Bussel, G., van Kuik, G., and Scarano, F. (2008). 3d stereo piv study of tip vortex evolution on a vawt. In EWEC 2008 - European Wind Energy Conference - Brussels

[21] Paraschivoiu, I. (2002). Wind turbine design with emphasis on Darrieus Concept. Polythecnic International Press.

[22] Pierre Tchakoua, René Wamkeue, Mohand Ouhrouche, Tommy Andy Tameghe, Gabriel Ekemb "A New Approach for Modeling Darrieus-Type Vertical Axis Wind Turbine Rotors Using Electrical Equivalent Circuit Analogy: Basis of Theoretical Formulations and Model Development", Energies 2015, 8, 10684-10717; doi:10.3390/en81010684, ISSN 1996-1073

[23] I. Paraschivoiu, "Wind turbine design: with emphasis on darrieus concept", 2002, Montréal, Québec, Canada:Polytechnic International Press

[24] Paraschivoiu, I. and Delclaux, F. (1983). Double multiple streamtube model with recent improvements. Journal of Energy, 7:250 - 255

[25] M. Raciti Castelli, A. Englaro, and E. Benini, "The Darrieus Wind Turbine: Proposal for a New Performance Prediction Model based on CFD”, Energy 36, 2011, pp. 4919-4934

[26] H. Dumitrescu, Al.Dumitrache, Fl. Frunzulica,A. Pal, V. Turbatu,TORNADO concept and realisation of a rotor for small VAWTs, INCAS BULLETIN, Volume 5, Issue 3/ 2013, pp. 69 - 75 ISSN 2066 - 8201

[27] K. Suffera, R.Usubamatovb, G. Quadir, K.Ismaild ,: Modeling and Numerical Simulation of a Vertical Axis Wind Turbine Having Cavity Vanes, 5th International Conference on Intelligent Systems, Modelling and Simulation, 2014

[28] I. Malael, L. Moutet, V. Dragan, "Numerical simulation of a vertical axis wind turbine for urban use", Applied Mechanics and Materials Vol. 811(2015) pp 333-338, Trans Tech Publications doi:10.4028 /www.scientific.net/AMM.811.333

[29] F. R. Menter, M. Kuntz, R. Langtry "Ten Years of Industrial Experience with the SST Turbulence Model”, turbulence,Heat and Mass transfer 4, 2003 Begell House, Inc

[30] Frisch U. Turbulence The legacy of A.N. Kolmogorov.Cambridge Univ. Press, 1995

[31] S.Ferreira, H.Bijl, G. Van Bussel,G van Kuik , "Simulating dynamic stall in a 2D VAWT", Journal of Physics ,Conferance Series 75,2007

[32] T. Chitsomboon, C. Thamthae, „Adjustment of $k-\omega$ SST turbulence model for an improved prediction of stalls on wind turbine blades“, World Renewable Energy Congress, 2011-Sweden

[33] C.F. Cuciumita, V.A. Vilag, V. Silivestru, I. Porumbel "Genetic Algorithm for Gas Turbine Blading Design", GT2011-46171, Proceedings of the ASME Turbo Expo 2011, Vancouver, Canada

[34] F.G. Florean, I. Porumbel, "Novel Algorithm for Geometrical Optimization of Flow Channels", Termotehnica, vol. 2, ISSN-L 1222-4057, 2015 